\title{
JALEA: an authentic and personal path to JApaneseLEArning
}

\author{
Mariotti, Marcella ${ }^{\mathrm{a}}$; Mantelli, Alessandro ${ }^{\mathrm{a}}$; Lapis, Giovanni ${ }^{\mathrm{a}}$
}

${ }^{\mathrm{a}}$ Department of Asian and North African Studies, Ca' Foscari University of Venice).

\begin{abstract}
This paper aims to present JALEA, an innovative web tool for the acquisition of the Japanese language dedicated to higher education learners. In particular it highlights the innovative learner-centered approach based on the self-guided discovery of grammar structures and words' meanings through the combined use of realia (multimedia contents referring to real-life situations in Japan), hyperlinks and interactive features such as pop-up dictionary, character-writing explanations, slow-motion option in video examples, etc. Moreover, it illustrates the ICT (Information and Communication Technology) characteristics of this web tool, permitting on the one hand the smooth working of the application on several platforms ( $p c$, tablet and smartphone); on the other, its sustainability and maintainability thanks to the implementation of a layer accessible to maintainers (backend) with several automatization features that facilitate the addition of more contents, also by personnel with low ICT knowledge or skills.
\end{abstract}

Keywords: Japanese Language; e-Learning; Foreign Language Education; Instructional Design; Authentic Learning in Interactive Media; Digital Humanities. 


\section{Introduction}

JALEA is a web tool ${ }^{1}$ for the acquisition of the Japanese language that addresses the following limits related to conventional didactic tools, such as grammar reference books or course textbooks for the Japanese language. However, listed below, such limits could apply in other situations concerning non-European languages, especially those with different and challenging writing systems and those referring to unfamiliar social-cultural practices and discourses.

- Difficulty, understood as the longer time and higher economic investment to master the spoken and written Japanese language among Euro-American learners (U.S. Department of the Army, 1996; Mariotti 2016: 8).

- Constrictive, tedious and time consuming methods due to top-down and predetermined teaching texts for academic learners or, on the contrary, improvised, inaccurate and ineffective language tools for the general non academic public.

- Fragmentation of separate reference tools (words dictionary, Sino-Japanese characters dictionary, grammar reference...).

- Artificial, tailored-up materials (images, audios, dialogues) which are still linked to the conception of "preparing" to speak a different language rather than a direct engagement with a foreign language as in real life. All the aforementioned materials have the shortcomings of creating an artificial environment and following abstract standards of language execution.

JALEA is the natural evolution of an earlier project BunpoHyDict (Mariotti 2008, 2011), which basically addressed the problems mentioned above but is tackling 3 critical issues:

1. How can data related to learner navigation be gathered so as to improve the learner experience?

2. How can it be usable through different devices (pc, tablets and smartphone as well)

3. As an exponentially growing project moving towards constant update with 'authentic materials', how can it be maintained and sustained?

JALEA tries to solve these issues featuring new technical add-ons such as an embedded pop-up dictionary, character writing explanations and, more importantly, adopting completely new architecture that will be explained in section 3 .

As a web tool, JALEA has been conceived to be used by both a self-learner without any assistance or guidance, and as a support or 'reference-book' by the foreign language

\footnotetext{
1 JALEA web address as of April 24, 2017: jalea.unive.it/jalea
} 
teachers in her/his class; however, ultimately these two modalities are meant to be combined together: on one hand, JALEA wants to exploit the role of pleasure in the autonomous discovery of new languages and ways of communicating, respecting the learner's autonomy, whilst on the other leaves more room for the foreign language teacher to explore a new and fundamental role as global citizens educator through dialogue, as critical pedagogy would suggest (Hosokawa, Otsuji, Mariotti 2016; Freire 1970).

Presently JALEA is written in Italian, as it addresses mainly the B.A. students of the Ca'Foscari University of Venice, but its approach and structure could just as well meet the needs of students of Japanese from any language background.

Japanese language learning web resources are scarce in Italian and university students rely mainly on English sites and apps, dictionaries or vocabulary-memorizing tools. Those few Italian sites consist mainly in practical suggestions for self-learning with links to external resources. There are a number of grammar lessons/articles in Italian, written in informal style, often inside blogs which features miscellaneous information about Japan. They almost reproduce grammar reference book patterns, missing the hyperlinks and authentic materials repositories, as well as the embedded words and Sino Japanese character dictionary.

\section{JALEA's structure and learning paths: the frontend}

The main elements of JALEA are clearly visible in the homepage: the menu at the top, and three different-coloured buttons on the bottom: Indice grammaticale ('grammatical index'), Immagini e foto ('images and photos') and Video ('video clips'). The top menu links to the following 5 sections:

1) Basics

This section provides the absolute beginner of Japanese with the first, essential information and knowledge about the Japanese language. It is organized in 8 tabs. In the first, the main Japanese grammar characteristics are summarized in 7 points. The other 5 tabs are then devoted to the unfamiliar writing system of Japanese, introducing the coexistence of 3 different components: Sino-Japanese characters, katakana and hiragana syllabaries. The latter two are listed in tables in which, with a mouse-over, a pop-up explains how they are written. The two last tabs, biblio/webliography and useful external links, offer more detailed information if required. 


\section{2) La storia ('history') \& 3) Il gruppo ('research group')}

The History section recalls the past projects (BunpoHyDict 2008, ITADICT 2010, EDUKANJI 2012) and experiences that lead to JALEA, and also provides further tools for Japanese learners. For example, the past project EDUKANJI (Mantelli 2012) is offered here as a specific learning tool for the comprehension and memorization of Sino-Japanese characters, thanks to its exercises. Finally the (manga style) research group presentation also wants to underline the light and playful albeit scientifically rooted approach of this web tool.

\section{3) Morfemi ('Morphemes' or 'grammatical items')}

By clicking on this link the learner visualizes the morphemes index with an additional menu for alphabetical search. This is one of the main components of JALEA, in which knowledge of the Japanese grammar is provided through the explanation of all grammatical items a student enrolled in a Ca' Foscari University of Venice bachelor's course is supposed to master by the end of her/his path. This index is also accessible by clicking the violet button.

\section{4) Video ('video clips') and 5) Immagini ('images')}

By clicking on these links the learner gains access to the other main components of JALEA, namely the repository images and clips referring to realia, i.e. authentic materials from real life situations in Japan, without any process of tailoring their contents to the level of the learner. Apart from providing a glimpse of what real Japanese language in real Japanese context is, these authentic materials were also chosen in view of the interest and pleasure of discovery that they should hopefully arouse in the learner's mind (Mariotti 2015). The clips and images indexes are also accessible by clicking respectively the green and yellow buttons in the home page. Given this main structure of JALEA, the learning path can be of a twofold nature. One starting from the need to know a specific grammar item; the other triggered by curiosity towards authentic materials and leading to a self-guided discovery and comprehension.

\subsection{Looking for a specific grammar item}

Let us assume, for example, that an Italian beginner studying Japanese wants to read an online Japanese newspaper. Although useful web tools already exist, like online dictionaries or pop-up dictionaries in English such as Rikaichan (an extension to be added to the browser which also de-inflects verbs), a learner of Japanese, especially a nonEnglish-speaking one, may want to understand the exact use of a specific grammar item in particular like, let's say, the particle $こ n i$ in its value (among others) as a temporal postposition in the phrase 五時半に go ji han $\underline{n i}$ ('at half past five'). Selecting the grammar item $\mathrm{s} / \mathrm{he}$ is searching for from the alphabetical list, the main page of that item 
(particle, idioms, suffix..) will appear, in this case the grammar item $こ n i$. The first impact will be with a photograph of authentic Japanese Language in use: a 'manner poster' inside a Odakyu bus in Mitaka-Tokyo. A green arrow indicates the grammar item inside the photograph, providing a visual example of its use. If clicked, the green arrow leads to a subsection explaining the use of the grammar item in that particular context. In addition to the photo, the components of the main page of a grammar item are:

- Basic information, namely the grammatical definition, an approximate translation and the general meaning/value underlying all the various uses.

- Links to additional information pages, namely the list of its various uses (as complements, in creating subordinates...), its construction (in case of inflective grammar items) plus further in-deep analysis.

- Links to related morphemes.

- Links to images and video clips featuring that morpheme.

By clicking on the additional information links, especially the ones concerning the specific uses, the learner will find practical schemes in which sample sentences are analysed with glosses and grammatical categorization of each component. Further examples of sentence patterns are given, voiced by audio clips by a non-professional speaker or by a voice synthesizer. Let us go back to the learner who needs to understand the postposition $n i$ in the above presented phrase go ji han ni. S/he could either be satisfied with the information given on the main page or may need to investigate further. By using a dictionary s/he could discover the meaning of the other words: go 'five', $j i$ 'hour', han 'half', and suppose that has something to do with an expression of time. Therefore, observing among the additional information links provided on the main page that $n i$ also functions as a complement of time in Italian (complemento di tempo determinato) s/he will click this link and verify that $\mathrm{s} / \mathrm{he}$ was right, thus hopefully feeling the pleasure of self-guided discovery that will reinforce this information in her/his brain (Caon 2006).

\subsection{Self-guided discovery}

The above cited self-guided discovery / self-guided comprehension is the core of the second learning path of JALEA, which ultimately makes it different from a simple digital transposition of a grammar reference. This learning path starts from the repositories of multimedia realia examples, which are selected from all kinds of media: representative novels read aloud (audio clips), newspaper articles, manga, anime, documentaries, movies trailers, printed and filmed commercials, road signs, music video clips, answering machines, automatic teller machines etc... For example, by clicking on the video clip's repository button and selecting one of them, the learner will be presented with: 
- The video clip, with full commands under the screen to stop, replay and slow it; and the link to the source of the example;

- A timed transcription of the text in Japanese, together with transliteration in Latin characters, all the sentences of which are highlighted when pronounced in the video clip. Moreover, by clicking on each sentence the video will replay from that point, allowing repetition and facilitating listening comprehension;

- A list of the links to the main pages of the grammar items related to the text;

- A link to the full translation of the text.

However, the main characteristic of JALEA consists in each grammar item of the text being linked to the specific additional information pages, enabling the learner to decode each particular use of grammar items inside a specific text. This function, along with an embedded pup-up Japanese-Italian dictionary that automatically appears when the mouse is over a word, provides the learner with virtually all s/he needs for the comprehension of the text. It goes without saying that JALEA can be used in the lecture theatre too. As explained above, each grammar item is explained from its basic meaning to its particular uses and exceptions, with plenty of tables, schemes and sample sentences. Alternatively, in the classroom a teacher may want to explain the use of a particular grammar item, starting with its use in real contexts (i.e. not starting with a general explanation). Each grammar item is listed with two links that lead to all the video clips and images featuring that particular item in its diverse uses. It should be noted, moreover, that the grammar items list also includes those grammar items that do not usually stand alone, but are considered variations of primary grammar items. For example the -cha ikenai expression "cannot be done" is a colloquial variation of the -te wa ikenai expression, which in turn is one of the various uses of the verbal -te conjunctive form. The -cha ikenai expression is collocated under the more general -te form, but if needed, it can be directly found by a simple alphabetical search in the morphemes' index. By clicking on -cha ikenai, it will then lead directly to the correspondent additional information section of the $-t e$ form page.

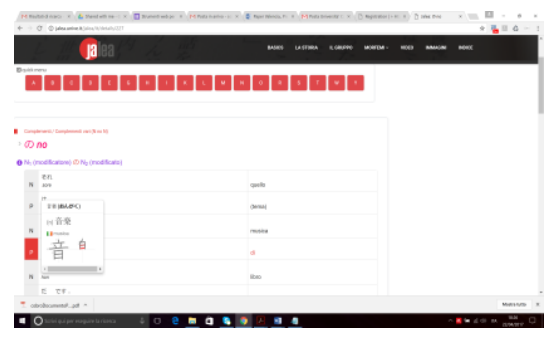

Figure 1. Grammar \& Pop-up Dictionary

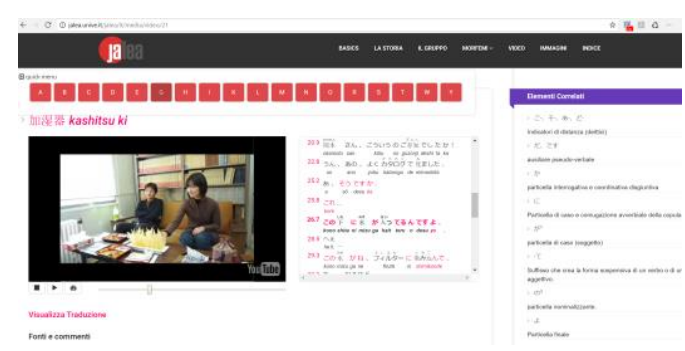

Figure 2. Text Syncing Functionalities 


\section{JALEA's ICT (Information and Communication Technology) Architecture}

JALEA has been developed using a client - server model architecture with a LAMP (Linux, Apache, MySq1/MariaDb, PHP/Python) stack software model. PHP has been used as server-side language and MySql as database. The Programming code has been organized in a Model-View-Controller Pattern with the usage of a framework called CodeIgniter, thus allowing the separation of the organization logic and presentation logic. The client component (the content visualized in the browser) has been developed using the Bootstrap library in a responsive format. This basically means that all the page content is resized and reorganized according to the window/device size, thus allowing a smooth application usage even in smartphones and tablets. Moreover, all the pages are AJAX-oriented, a technology that allows data to be sent and retrieved from the server and for the contents to be updated without reloading the page. Thanks to this approach, pages are loaded and displayed faster. At a macrostructural level the application can be divided in 2 main sections: a) public b) private.

a) Public area or FrontEnd

This is the section that all users can access. Some part of the public area will be restricted and access will be granted by the login-password authentication method.

b) Private Area or BackEnd

This is the Control Panel accessible to the administrators through login and password. In the Control Panel administrators can edit, insert or delete all the contents such as tags, morpheme wrapping and examples. Administrators can also upload photos, audio, links to YouTube videos or create voice using text-to-voice libraries. Managing video-, and audiovoice contents requires a considerable effort. Where possible several activities have been automatized. For example: there is no need to insert the kana (syllabaries) and romaji (Latin characters) transliteration of the sentence samples manually as they are automatically converted by the Mecab morphological analyser. If a native-speaker audio file is not uploaded for a certain sentence, this can be automatically converted to speech with a text-to-speech automatic engine. Moreover, a voice file can be created ad hoc through the control panel apposite function by selecting one of the two text-to-speech engines available and by changing parameters such as character voice, pitch and speed. Finally, by using the YouTube API, the scripts prepared by the administrator can be synced with the uploaded video. This allows the user to navigate the video and listen to the same sentence over and over if needed. The Client Server Approach and the implementation of a Database Oriented logic makes it possible to gather data from learner navigation, and in so doing, to face the first critical issue that emerged in previous research projects (see p.1). The Bootstrap Library used in the client area development responds to the second issue as it makes Jalea usable through different devices. The last third issue regarding project 
maintainability has been tackled by dividing the macrostructure into two sections: frontend and backend, so that contents can be easily updated by any approved user. Database structure is ready for multi-language implementation since multi-language fields are already divided in different tables.

\section{Conclusion}

At the time we are writing this paper, JALEA structure and contents are currently in the development phase but we will be able to gather feedback from students from March 2017 on. The features explained so far are targeted to the learner's listening/reading comprehension (passive competences) and grammar acquisition needs, so our next step (2018) will be to add a section aiming at "language production" skills. Thanks to the flexible database structure of JALEA, we plan to provide an index search of the various grammar items starting with their meanings and communicative functions (i.e. 'how do I say "I want to..." in Japanese'). Moreover, the selection of the first communicative functions will be based upon the results of the workshop Action Research Zero (Mariotti, Ichishima, Hosokawa 2017) based on pioneering FLT theories (Hosokawa, Take 2012) in which absolute beginners only faced grammar in the authentic context of a community dialogue. In lieu of conclusion, we would like to state why, with this paper, we want to disseminate information about a project which is still in the making: as an applied research project in language education it is in constant evolution and in constant need of new perspectives and new problems that we hope we will receive from our readers. 


\section{References}

Caon F. (2006). Pleasure in Language Learning and Teaching: a Methodological Challenge. Perugia: Guerra Edizioni.

Freire, P. (1970). Pedagogy of the Oppressed. New York: Continuum.

Hosokawa, H. \& Take, K. (eds.). (2012). Shokyū kara hajimaru "katsudōgata kurasu" ("Active-type class" starting from the beginner level). Tokyo: 3A Corporation.

Hosokawa, H., Otsuji E., \&Mariotti, M. (eds.). Shiminkeisei to kotoba no kyōiku (Citizenship Formation and Language Education). Tokyo: Kuroshio.

Mantelli, A. (2012) EDUKANJI http://lingue.cmm.unive.it/course/view.php?id=239

Mariotti, M (2008), BunpoHyDict, http://www.bunpohydict.com/

Mariotti, M. \&Mantelli A. (2010) ITADICT http://www.a4edu.com/

Mariotti M. (2011). BunpōHyDict and e-learning 2.0 in TAKESHITA T. (ed.), Insegnamento della lingua giapponese e Studi giapponesi: didattica e nuove tecnologie in Contesti linguistici (Japanese Language Teaching and Japanese Studies: Didactics and new technologies in Linguistic Contexts) (pp.47-57) Bologna: CLUEB.

Mariotti, M. (2015) Japanese Language Learning through Authentic Materials: Insights from an Italian University Case Study. In Calvetti, P. \&Mariotti, M. (eds.), Contemporary Japan. The Challenge of a World Economic Power during a Period of Transition (pp. 131-148).Venezia: EdizioniCa' Foscari.

Mariotti M., Ichishima N., \& Hosokawa H. (2017). Practical Studies in Japanese Language Education: a report about Action research Zero Workshop in Venice (Italy), Annali di Ca' Foscari. Serie orientale, 54, (forthcoming).

U.S. Department of the Army, (1996). Personnel selection and classification: Army linguist management (Army Regulation 611-6). Washington, DC: USAPA. 